\title{
Serial position, primacy and the von Restorff isolation effect
}

\author{
L. R. GOULET, RONALD N. BONE AND D. D. BARKER ${ }^{l}$ \\ WEST VIRGINIA UNIVERSITY
}

The von Restorff Isolation Effect was studied in serial learning where the ordinal position of the isolated items was manipulated. Also, for different groups of Ss, the starting position in the serial list on Trial 1 was either at Item 1 (structural beginning) or at Item 5 (temporal beginning). Isolating the fifth item in the structural beginning treatment accelerated the learning of that item, with minimal effects when the first or last item was isolated. The data supported an hypothesis that perceptual isolation changes the order in which the isolated item is learned rather than accelerating the learning of that item as a response. Similar effects were found for the temporal beginning treatments when Item 1 or 8 was isolated. However, isolation of Item 5 retarded the learning of that item. The latter results were attributed to $S$ s confusion in selecting between Item 5 and 1 as the anchor point in the list.

Bone \& Goulet (in press) have recently demonstrated that perceptual isolation in a serial list facilitates the learning of an item that occupies the middle serial position but that facilitation is minimal when beginning or end items are isolated. These results are in accord with predictions that may be derived from Jensen's (1962a, b) empirical theory of serial learning. However, an alternative interpretation explains the minimal isolation effects for beginning and end items in terms of ceiling effects due to the very rapid learning of these items even without isolation (Bone \& Goulet, in press).

The present experiment provided an additional test of the effects of isolation. Different groups of Ss were started at Item 5 in an eight item list (temporal beginning) versus other groups of Ss at the normal starting order indicated by an asterisk (structural beginning). The temporal beginning groups saw the eight items in the list in the order 5678*1234, which placed Items 8 and 1 in the middle of the list during its first exposure. If isolation is related to primacy effects (e.g., Glanzer \& Peters, 1962), the effects of isolation (Jensen, 1962a, b) should be equal and pronounced for lists where Items 1 or 8 were isolated versus a list where Item 5 was isolated.

\section{Materials}

The serial lists were composed of eight two syllable nouns (low similarity) with a Thorndike-Lorge " $L$ " count range of $1-3$ per 4.5 million. Two different random orders of the eight nouns were constructed to control for item difficulty. For each of the list and starting conditions, different treatments had Items 1, 5, or 8 isolated (typed in red). All nonisolated items were typed in black. The control treatments had all items typed in black. An asterisk was used to identify the structural starting point of the list. Procedure

The Ss were 80 volunteers who were randomly assigned to one of the 16 treatments with the restriction of equal Ns for each block of 16 Ss. Most of the Ss had prior experience with paired-associate learning, but none had previously learned a serial list. Each $\mathrm{S}$ was tested individually and given standard instructions regarding serial learning and the anticipation method. All lists were presented on a Lafayette memory drum at a $2 \mathrm{sec}$ rate, with a $2 \mathrm{sec}$ intertrial interval. No mention was made of the starting position nor that any of the items would be isolated. Learning was taken to a criterion of one errorless trial, which involved anticipating Items 1-8 consecutively for all treatments.

\section{Results and Discussion}

The mean trials to criterion for the structural beginning treatments were: $12.4,11.7,11.9$, and 8.3; for the temporal beginning treatments they were: $17.3,12.8,15.4$, and 19.4 , with either Item 1,5 , or 8 isolated and the $\mathrm{C}$ treatments, respectively. The temporal beginning lists were more difficult than the structural beginning lists $(F=9.30, d f=1 / 72, p<.01)$. Isolation of individual items did not accelerate the learning of the entire list relative to the control list

Table 1. Mean Correct Responses Per Exposure as a Function of Serial Position

\begin{tabular}{|c|c|c|c|c|c|c|c|c|c|}
\hline & $\begin{array}{l}\text { Isolation } \\
\text { Treatments }\end{array}$ & 1 & 2 & 3 & 4 & 5 & 6 & 7 & 8 \\
\hline Structural & 1 & .737 & .730 & .426 & .754 & .517 & .414 & .430 & .520 \\
\hline \multirow[t]{4}{*}{ Beginning } & 5 & .620 & .480 & .553 & .626 & .552 & .551 & .529 & .628 \\
\hline & 8 & .744 & .638 & .544 & .659 & .547 & .455 & .452 & .610 \\
\hline & $\mathrm{C}$ & .724 & .834 & .631 & .729 & .498 & .491 & .490 & .569 \\
\hline & Grand Mean & .706 & .671 & .539 & .672 & .529 & .478 & .475 & .582 \\
\hline Temporaì & 1 & .711 & .534 & .471 & .505 & .376 & .582 & .415 & .439 \\
\hline \multirow[t]{4}{*}{ Beginning } & 5 & .626 & .500 & .412 & .594 & .364 & .613 & .639 & .524 \\
\hline & 8 & .731 & .579 & .464 & .608 & .431 & .581 & .464 & .533 \\
\hline & C & .593 & .512 & .400 & .592 & .501 & .473 & .377 & .410 \\
\hline & Grand Mean & .665 & .531 & 437 & .575 & .431 & .562 & .474 & .477 \\
\hline
\end{tabular}


Table 2.

Mean Rank and Rank-Difference Scores for the Isolation Treatments

\begin{tabular}{crrr} 
& \multicolumn{1}{c}{1} & 5 & 3 \\
\hline $\begin{array}{c}\text { Structural Beginning } \\
\text { E }\end{array}$ & 2.90 & 4.38 & 4.20 \\
C & 3.60 & 5.80 & 4.65 \\
C-E & +.70 & +1.45 & +.45 \\
Temporal Beginning & & & \\
E & 2.70 & 6.60 & 4.75 \\
C & 3.65 & 4.40 & 5.35 \\
C-E & +.95 & -2.20 & +.60
\end{tabular}

( $F<1, d f=3 / 72)$, and no interaction was evidenced ( $F=1.59$, df $=3 / 72$ ).

Table 1 presents the mean correct responses per exposure at each serial position for each treatment. This measure was derived for each $\mathrm{S}$ by determining the number of correct responses given at each serial position and dividing these scores by the number of times that item had been exposed during learning. This measure permitted correction for the one additional exposure of Items $5,6,7$, and 8 (relative to Items 1, 2, 3, and 4) for the temporal beginning treatments. Only the effect due to serial position was significant $(F=10.22, d f=7 / 504, p<.001) . A$ slight serial position curve (Table 1) can be discerned for both the structural and temporal beginning treatments. No other effects approached significance.

The primary data concerned the magnitude of the Isolation effect as a function of serial position. Because of the flat serial position curves obtained, the data were analyzed in terms of a relative measure. For each $S$ the items were ranked in terms of the number of correct responses per exposure. Following this, the rank of the isolated item for each $S$ in the isolation treatments was subtracted from the mean rank of the appropriate item in the control list. Table 2 presents the mean rank with which the isolated items were learned for each of the experimental treatments, the mean rank for the comparable items in the control treatment, and the rank difference scores $(C-E)$. A rank of 1 was assigned to the item which was learned first, etc. For the structurai beginning treatments, the greatest isolation effect occurred at position 5, with minimal effects of isolation at positions 1 and 8. For the temporal beginning treatments, greater effects of isolation were found at positions 1 and 8 relative to position 5. In fact, isolation at position 5 retarded the learning of that item. The statistical analysis indicated a significant Starting Order by Serial Position interaction $(F=5.83$, $\mathrm{df}=2 / 54, p<.01$ ). In addition, facilitative effects of isolation for the structural beginning treatments were slightly greater than those for the temporal beginning treatments $(F=3.68, d f=1 / 54, p<.10)$. In fact, the overall effect of isolation for the temporal be- ginning treatments was slightly negative. Of course, the latter effect can be attributed to the pronounced negative effect of isolation occurring at position 5 . The main effect of isolation did not approach significance in this analysis $(F=1.63, \mathrm{df}=2 / 54)$.

The data obtained in the present experiment support Jensen's (1962b) hypothesis that perceptual isolation of an item in a serial list changes the order in which it is learned. This effect is especially apparent ( $\mathrm{C}-\mathrm{E}$ scores) for the data from the structural beginning treatments. The data from the temporal beginning treatments, however, require further interpretation. The isolation of Item 5 , in combination with the temporal beginning treatment, very likely confused Ss with regard to the starting position or anchor point in the list, with Ss' subsequent choosing of Item 1 as the anchor. In order to prevent further confusion, then, Ss disregarded the item until most of the items in the list were learned. The data from Table 2 indicate that Item 5 was learned almost last in the temporal beginning list $(\overline{\mathrm{X}}$ rank $=6.6)$ when it was isolated, versus obtaining a mean rank of 4.4 when it was not isolated. When the isolation item occupied position 1 or position 8 this type of confusion would not be expected because the beginning or end items, in themselves, are anchor points in a serial list.

Without this type of confusion, the order of learning Items 1 or 8 when they were isolated would not differ from the order in which they were learned in the structural beginning treatments. The data from Table 2 indicate this to be the case. The effects of isolation (C-E scores) are similar and of the same magnitude for Items 1 and 8 for both temporal beginning and structural beginning treatments. Also the mean rank with which Item 1 was learned was similar for the temporal beginning and structural beginning treatments. This was true for both the $\mathrm{C}$ and $\mathrm{E}$ groups and for the same comparison when Item 8 was isolated. The conclusion, therefore, is that isolation affected the order of learning an isolated item in the same manner for the structural beginning and temporal beginning treatments except when Item 5 was isolated.

\section{References}

BONE, R. N., \& GOULET, L. R. Serial position and the von Restorff isolation effect. $J$. exp. Psychol, in press.

GLANZER, M., \& PETERS, S. C. Re-examination of the serial position effect. J. exp. Psychol., 1962, 64, 258-266.

JENSEN, A. R. An empirical theory of the serial position effect. $J$. Psychol., 1962a, 53, 127-142.

JENSEN, A. R. The von Restorff isolation effect with minimal response learning. J. exp. Psychol., 1962b, 64, 123-135.

SALTZ, E., \& NEWMAN, S. E. The von Restorff isolation effect: Test of the intralist association assumption. J. exp. Psychol., 1959, $58,445-451$.

Note

1. Now at the University of Utah. 